\title{
Mineração
}

\section{Pilar-barreira entre painéis de lavra para a mina de carvão}

\author{
(Barrier pillar between production panels in coal mine)
}

\author{
André Cezar Zingano \\ Engenheiro de Minas, Professior Dr. do DEMIN, UFRGS \\ E-mail:andrezin@ufrgs.br \\ Jair Carlos Koppe \\ Engenheiro de Minas/Geólogo, Proessor Dr. do DEMIN, UFRGS \\ E-mail:jkoppe@ufrgs.br \\ João Felipe C.L. Costa \\ Engenheiro de Minas, Professor Dr. do DEMIN, UFRGS \\ E-mail: jfelipe@ufrgs.br
}

\section{Resumo}

A função de um pilar-barreira é proteger o painel de lavra em operação contra a transferência de pressões imposta pelos painéis de lavra adjacentes nos quais os pilares foram recuperados. No caso das minas de carvão em Santa Catarina, o pilar-barreira tem função de proteger o eixo da mina e os painéis em atividade contra a ruptura de pilares inesperada dos painéis de lavra antigos que já encerraram sua operação. O objetivo desse trabalho é verificar a validade do método empírico para o dimensionamento de pilar-barreira apresentado em Peng (1986) por meio da simulação numérica de uma geometria de lavrapadrão, que é aplicada para minas de carvão. Modelos numéricos em duas dimensões foram construídos obedecendo à geometria dos pilares do eixo e do painel de lavra para diferentes profundidades da camada Bonito. Foram consideradas as propriedades das materiais que formam o sistema piso-pilar-teto. Os resultados mostram que o método empírico é válido para a geometria projetada, onde os pilares do eixo não sofrem sobrecarga devido à lavra do painel e nem o teto sofre ruptura devido à redistribuição das tensões.

Palavras-chave: Carvão, lavra subterrânea, pilar-barreira.

\begin{abstract}
The function of the barrier pillar is to protect the mining panel in activity from the abutment load of adjacent mining panels that were mined. In the case of underground mines in Santa Catarina State, the barrier pillar has functioned to protect the main entries of the mine against pillar failure from old mining panels. The objective of this paper is to verify the application of the empirical method to design barrier pillars as proposed by Peng (1986), using numerical simulation following the mining geometry of the coal mines in Santa Catarina State. Two-dimensional numerical models were built taking into account the geometry of the main entries and mining panels for different overburden thickness, and considering the geomechanical properties for the rock mass that forms the roof-pillar-floor system for the Bonito coal vein. The results of the simulations showed that the empirical method to determine the barrier pillar width is valid for the studied coal vein and considered mine geometry. Neither did the pillar at the main entry become overstressed due to adjacent mine panels, nor did the roof present any failure due to stress redistribution.
\end{abstract}

Keywords: Coal, underground mining, barrier pillar. 


\section{Introdução}

Até o passado recente, a utilização de pilar-barreira entre o painel de lavra e o eixo da mina (ou entre painéis de lavra) não era prática comum nas minerações de carvão em Santa Catarina. A baixa recuperação da jazida e a falta de informação sobre os resultados catastróficos de um colapso massivo de pilares eram argumentos apresentados para essa prática.

Recentemente, houve três colapsos de pilares que interromperam a lavra por mais de um mês e levaram a perda de jazida para quase dois anos de produção. A interrupção inesperada das atividades de lavra motivou o corpo técnico das empresas retomarem a produção de carvão implementando pilares-barreira entre os painéis de lavra e o eixo das minas.

O objetivo desse trabalho é verificar a validade de aplicação do método empírico proposto por Peng (1986) para o dimensionamento de pilar-barreira, por meio de modelos numéricos que foram realizados no FLAC-2D versão 4. Esses modelos obedecem à geometria dos pilares e galerias que está apresentada nos projetos típicos de minas de carvão de Santa Catarina.

A seguinte metodologia foi utilizada para atingir o objetivo:

- Determinar a geometria dos modelos baseada em projetos de lavra e em função da profundidade da camada Bonito.

- Determinar as propriedades dos materiais que formam o sistema piso-pilar-teto.

- Construir os modelos numéricos para diferentes profundidades da camada Bonito, os quais ocorrem nas diversas jazidas em Santa Catarina.

- Realizar simulação numérica da lavra, obedecendo a uma seqüência de lavra.

- Concluir a validade do método empírico para dimensionamento de pilarbarreira de Peng (1986) em função da variação da tensão vertical nos pila- res do eixo e no pilar-barreira e nos deslocamentos do teto imediato nas galerias do eixo.

\section{Pilar-barreira por meio de métodos empíricos}

Pilar-barreira é um elemento essencial em lavra em recuo em grandes profundidades. Tradicionalmente, pilaresbarreira têm sido empregados para isolar painéis em atividade de painéis adjacentes que encerraram suas atividades como uma técnica de controle de tensões. Com o aumento da profundidade, pilares-barreira tornam-se mais importantes para suportar a transferência de pressão dos painéis adjacentes que sofreram abatimento do teto devido à lavra em recuo. Uma questão importante de projeto é: qual a largura do pilar-barreira? Campoli et al. (1995) e Peng (1986) apresentam algumas metodologias de dimensionamento do pilar-barreira entre painéis de lavra. No exemplo apresentado em Campoli et al. (1995), ele demonstrou que não seria necessário utilizar pilar-barreira para profundidades menores que $308 \mathrm{~m}$ (1000 ft), mas a largura do pilar-barreira deve variar entre $45.72 \mathrm{~m}$ (150 ft) até $73.15 \mathrm{~m}$ (240 ft) para coberturas desde $365.76 \mathrm{~m}$ (1200ft) até $670.56 \mathrm{~m}(2200 \mathrm{ft})$.

Mark (?) afirma que não será necessário aplicar pilar-barreira se não ocorrer recuperação dos pilares por meio da lavra em recuo, porque os pilares fariam função de suporte do maciço rochoso de cobertura. Entretanto, Mark não menciona a possibilidade de ocorrer ruptura dos pilares devido ao tempo e devido ao efeito do desmonte sobre a resistência final do pilar.

Existem diferentes equações empíricas para calcular a largura do pilar-barreira (Peng, 1986), sendo essas fórmulas dependentes da profundidade da camada de carvão. Peng (1986) propõe que a largura do pilar-barreira deve ser calculada pela fórmula:

$w p=0.1 h+45$

Sendo que essa fórmula é calculada em pés (feet), no sistema inglês. Essa fórmula foi adotada para calcular a lar- gura do pilar-barreira para as simulações numéricas que foram construídas para este trabalho.

\section{Simulação numérica}

A simulação por meio de métodos numéricos como método dos elementos finitos ou método das diferenças finitas deve obedecer às condições de geometria e propriedades dos materiais do local que se está estudando. Para que essas condições sejam obedecidas, o modelo numérico deve possuir as seguintes etapas:

- Geometria e geologia do modelo, baseado em informações do projeto de lavra e sondagens.

- Condições de contorno e restrições nas bordas do modelo para simular a continuidade do meio.

- Propriedades dos materiais (maciço rochoso) que são encontrados no local e que formam o modelo, sendo essas propriedades baseadas em critérios de classificação.

- Campo de tensões inicial do modelo, baseado em medidas de tensões ou métodos empíricos.

- Seqüência de escavação das galerias para simular a redistribuição das tensões e deslocamentos do maciço provocados pela escavação.

- Análise dos resultados para determinar se o maciço rochoso ou o tipo de tratamento empregado para controle de deformações é satisfatório (ou não).

\subsection{Geologia e propriedades dos materiais}

A geologia e as espessuras das camadas foram baseadas em 3 (três) furos de sondagem que foram fornecidos pela Carbonífera Metropolitana. Os perfis dessas sondagens mostram uma variação natural das espessuras de cada camada de rocha, juntamente com a pro- 
André Cezar Zingano et al.

fundidade. Foi adotada a geologia para a simulação numérica, conforme a Figura 1. As espessuras de cada camada foram atribuídas em função da média das espessuras, com exceção da camada de carvão, que foi adotada de acordo com a espessura maior (3.8m).

As propriedades geomecânicas do maciço rochoso do sistema piso-pilarteto e da cobertura do modelo foram determinadas a partir de informações fornecidas pelas empresas e da tese de doutorado de Zingano (2002). A partir dessas informações, foram estimadas as qualidades das rochas por meio da classificação RMR de Bieniawski (1973 e 1989) e por meio do GSI (Geological Strength Index; Hoek \& Brown, 1997), sendo que o GSI é determinado a partir do RMR menos 5, com o parâmetro "presença de água” fixado em 10. A Tabela 1 mostra os valores de GSI para as rochas que formam o maciço rochoso para os modelos desse trabalho.

O valor do GSI (RMR) do carvão é compatível para um maciço mais resistente se comparado ao siltito e ao argilito. Entretanto é um valor baixo de qualidade devido à alta densidade de fraturas. Em Zingano (2002) foi estimado o valor de 43 para o GSI, mais próximo ao valor do siltito e do argilito. A equipe da John T. Boyd determinou uma qualidade de maciço para a camada mais alta, com valor do GSI em torno de 68. Essa diferença pode ser explicada pela diferença de mapeamento das fraturas que foi realizado em Zingano (2002) e pela equipe da John T. Boyd em 1998. O mapeamen- to realizado por Zingano foi feito por meio de janelas nas paredes dos pilares e o mapeamento realizado pela John T. Boyd foi feito por meio de scanline, anotando as juntas mais importantes sem considerar descontinuidades menores que influenciam no resultado do RQD da camada.

Os dados dos ensaios e da classificação geomecânica foram inseridos no programa RocLab $1.0^{\circledR}$ da empresa Rocscience Inc., o qual aplica o critério de Hoek e Brown (1997) para estimar as propriedades do maciço rochoso. A Tabela 2 apresenta os valores das propriedades geomecânicas para as rochas do sistema piso-pilar-teto para a camada Bonito, os quais foram utilizados nas simulações numéricas desse trabalho.

Os materiais seguem o modelo elasto-plástico perfeito, i.e, quando o material atinge sua tensão de ruptura ele entra em regime plástico sem modificar sua tensão máxima admissível. Esse modelo de material consegue representar o comportamento dos materiais na realidade sem exigir grande quantidade de memória do computador.

\subsection{Geometria dos modelos e seqüência de lavra}

A camada Bonito encontra-se em diferentes profundidades na região de Criciúma. Logo, é necessário realizar uma simulação, cada uma dessas profundidades. Além disso, para cada uma dessas profundidades existem dimensões de pilares e galerias correspondentes.

Tabela 1 - Valores de GSI e resistência à compressão uniaxial (sci) para as rochas do maciço rochoso para a camada Bonito.

\begin{tabular}{c|c|c}
\hline Rocha & $\sigma c i(\mathbf{M P a})$ & GSI (RMR) \\
\hline Arenito maciço & 77.0 & $77(82)$ \\
\hline Arenito laminado & 75.0 & $70(75)$ \\
\hline Argilito na camada & 16.8 & $50(55)$ \\
\hline Carvão camada Bonito & 20.9 & $43(48)$ \\
\hline Siltito & 39.7 & $45(50)$ \\
\hline
\end{tabular}

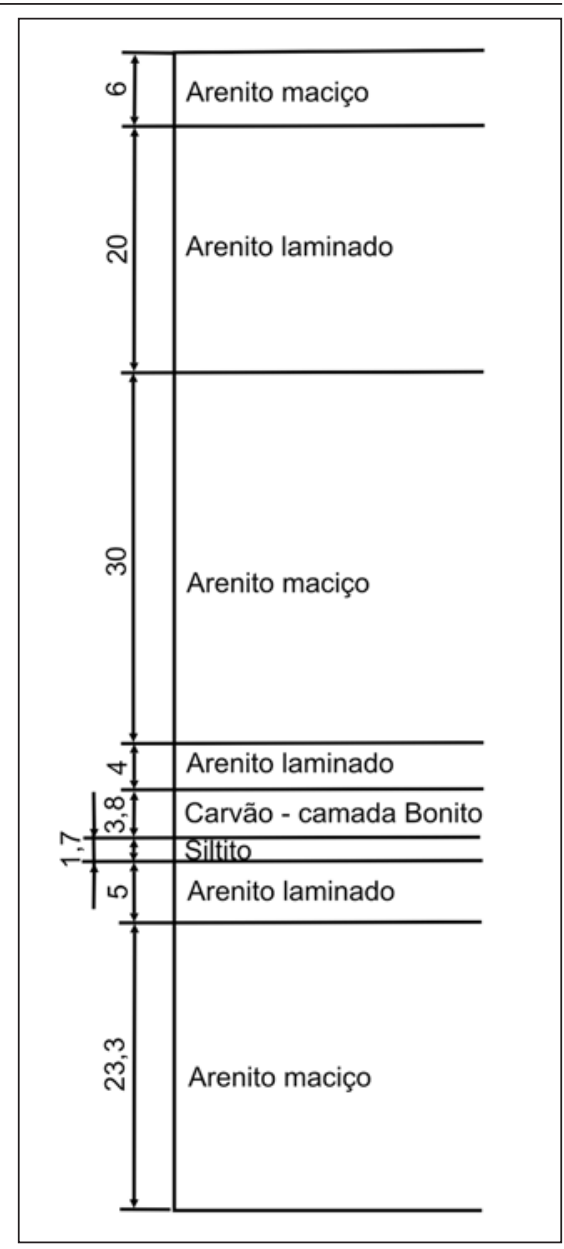

Figura 1 - Seqüência geológica e espessuras das rochas para a simulação numérica (medidas em metros).

Para as simulações desse trabalho, foram adotadas as profundidades da camada Bonito, que são representativas das jazidas. Os tamanhos dos pilares e larguras das galerias, que foram adotados nas simulações, também estão baseados em projetos de lavra das empresas. A Tabela 3 mostra a profundidade, tamanho do pilar e largura do pilar-barreira para cada simulação. Para cada profundidade da camada, foram utilizados dois tamanhos de pilares e largura do pilar-barreira, conforme a Tabela 3. A largura da galeria é fixada em 6 metros.

Os modelos numéricos são realizados no FLAC ${ }^{\circledR}$ em duas dimensões que representam uma seção vertical que abrange parte do eixo, o pilar-barreira e o painel de lavra (Figura 2). Essa seção está posicionada no centro do painel de lavra. O eixo da mina é representado por 
Pilar-barreira entre painéis de lavra para a mina de carvão

Tabela 2 - Propriedades das rochas que foram adotadas nas simulações numéricas.

\begin{tabular}{c|c|c|c|c|c|c}
\hline Rocha & $\begin{array}{c}\text { mi } \\
\text { (GSI index) }\end{array}$ & $\begin{array}{c}\text { Coesão } \\
\text { (MPa) }\end{array}$ & $\begin{array}{c}\text { Ângulo de } \\
\text { atrito }\end{array}$ & $\begin{array}{c}\text { Resist. do } \\
\text { maciço (MPa) }\end{array}$ & $\begin{array}{c}\text { Módulo Young } \\
\text { (MPa) }\end{array}$ & $\begin{array}{c}\text { Razão de } \\
\text { Poisson }\end{array}$ \\
\hline Arenito maciço & 7.28 & 8.2 & 30.4 & 23.7 & 54532.9 & 0.20 \\
\hline Arenito laminado & 7.28 & 7.1 & 28.5 & 14.4 & 38828.1 & 0.20 \\
\hline Argilito camada & 3.68 & 0.8 & 16.6 & 1.6 & 5170.6 & 0.27 \\
\hline Carvão Bonito & 6.63 & 1.8 & 26.9 & 4.7 & 34606.9 & 0.25 \\
\hline Siltito & 23.9 & 2.6 & 20.6 & 5.2 & 6138.3 & 0.25 \\
\hline
\end{tabular}

duas galerias, meio pilar e um pilar inteiro, simulando a simetria do modelo, i.e., o eixo é cercado por dois painéis de lavra. O painel de lavra é representado por sete galerias

A Figura 2 mostra a geometria dos pilares-barreira e pilares dos painéis para a situação da camada em 100 m de profundidade, tamanhos de pilares de $12 \mathrm{~m}$ e pilar-barreira de $24 \mathrm{~m}$, adotados nesse trabalho. Os demais tamanhos de pilares e profundidades seguem o mesmo princípio.

A seguinte seqüência de lavra foi considerada nas simulações:

- Maciço rochoso sem escavação com as tensões virgens.

- Escavação das galerias do eixo da mina.

- Aplicação de reforço de teto nas galerias do eixo.

- Escavação das travessas do painel de lavra e construção do pilar-barreira.

O modelo numérico adotado nesse trabalho é o modelo com deformação no plano do modelo (plain-strain). Logo, devem ser consideradas as tensões horizontais no plano do modelo e perpendicular ao plano do modelo.

Inicialmente o modelo é carregado com as tensões virgens do maciço rochoso, considerando a razão entre ten-
Tabela 3 - Geometria dos modelos numéricos para a simulação do pilar-barreira.

\begin{tabular}{c|c|c}
\hline $\begin{array}{c}\text { Espessura de } \\
\text { cobertura (m) }\end{array}$ & Larguras do pilar $(\mathbf{m})$ & $\begin{array}{c}\text { Larguras do pilar- } \\
\text { barreira }(\mathbf{m})\end{array}$ \\
\hline 100 & 12 e 20 & 24 e 34 \\
\hline 200 & 12 e 20 & 24 e 34 \\
\hline 300 & 20 e 30 & 34 e 44 \\
\hline 400 & 30 & 44 \\
\hline
\end{tabular}

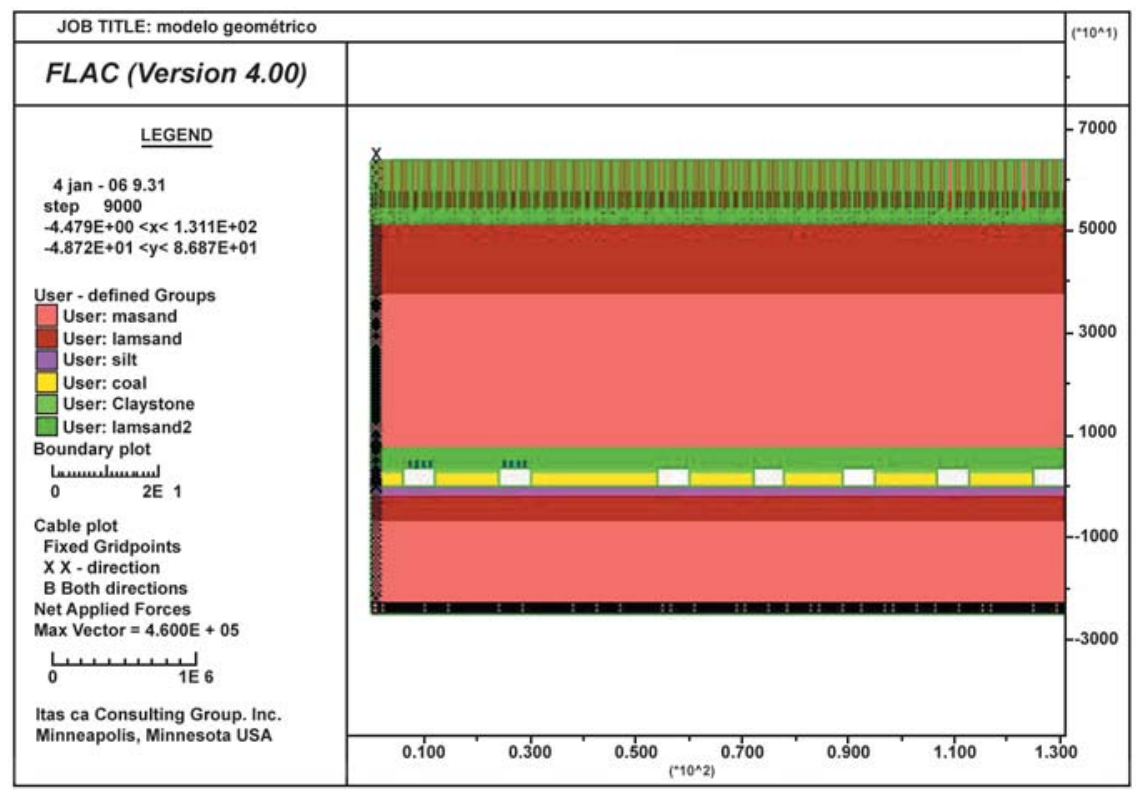

Figura 2 - Modelo geométrico das simulações (desenho sem escala). 
André Cezar Zingano et al.

são horizontal e tensão vertical igual a 1 (um). Esse fator foi adotado devido à falta de medidas de tensões naturais (ou virgens) na região e por não haver evidências de valores elevados de tensões horizontais. A espessura de cobertura é representada por meio da aplicação de pressão no topo do modelo, sendo que o valor dessa pressão representa a espessura de cobertura, subtraindo a espessura de cobertura existente no modelo (60 metros). A Tabela 4 mostra as pressões aplicadas ao topo do modelo e as tensões em posições importantes dentro do modelo. Essa tabela tem como objetivo balizar e verificar as tensões iniciais dos modelos numéricos em função da profundidade que se quer simular.

A seqüência de escavação das galerias do eixo e as travessas do painel de lavra têm objetivo de simular a lavra, a escavação é representada no modelo considerando a transformação dos elementos que formam as galerias da mina em elementos nulos. Os elementos são selecionados e anulados no modelo e, conseqüentemente, as tensões verticais e horizontais se redistribuem pelo maciço rochoso alterando o estado de tensões e as condições de plasticidade dos elementos próximos as escavações.

O suporte do teto para as galerias do eixo foi baseado no tipo de suportepadrão, que é aplicado atualmente pela maioria das empresas.

O FLAC ${ }^{\circledR}$ simula o suporte (ou reforço) de teto com parafusos e tirantes por meio de um elemento estrutural chamado de cable. Esse elemento estrutural requer uma série de dados geométricos e propriedades do tirante e da resina. Alguns dados que o FLAC requer para a simulação do tirante não são de conhecimento prévio nem foram medidos. Entretanto as informações fornecidas foram suficientes para determinar todos os parâmetros necessários para a simulação do reforço do teto. O manual do FLAC, onde se mostra o elemento estrutural cable, apresenta os procedimentos para determinar todos os parâmetros necessários para a simulação de um tirante.
O reforço do teto é realizado por 4 parafusos de $1.4 \mathrm{~m}$ de comprimento em linha com $1.3 \mathrm{~m}$ de espaçamento entre linhas e 1.3 m de distância entre parafusos na mesma linha. A distância da parede do pilar ao primeiro parafuso é de 1.05 metros. A ancoragem dos parafusos é feita com resina em coluna total. O diâmetro do parafuso é de 19 mm e o diâmetro do furo é de $31 \mathrm{~mm}$. A Tabela 5 apresenta os parâmetros para a simulação do reforço do teto para as galerias do eixo. O reforço do teto é aplicado ao modelo imediatamente após a escavação das galerias.

A escavação das travessas do eixo é feita após a escavação das galerias do eixo e aplicação do reforço do teto. A escavação de travessas é realizada de uma única vez, para economizar tempo de processamento e memória do computador, sem prejudicar a validade dos resultados.

Foram escavadas 7 (sete) travessas, de forma a definir uma distância do pilarbarreira segura, sobre o carregamento do pilar-barreira e realizadas alterações de tensões sobre os pilares do eixo.

A cada uma das etapas da seqüência de lavra para as simulações, os resultados são armazenados, podendo-se verificar as distribuições das tensões e deformações ao redor das escavações.

Foram aplicados pontos de controle, simulando instrumentos de monitora-

Tabela 4 - Pressões e tensões nos modelos numéricos para as profundidades que foram simuladas.

\begin{tabular}{c|c|c|c|c}
\hline $\begin{array}{c}\text { Profundidade } \\
(\mathbf{m})\end{array}$ & $\begin{array}{c}\text { Tensão vert } \\
\text { no topo do } \\
\text { modelo } \\
\text { (MPa) }\end{array}$ & $\begin{array}{c}\text { Tensão vert } \\
\text { na base do } \\
\text { modelo } \\
\text { (MPa) }\end{array}$ & $\begin{array}{c}\text { Tensão vert } \\
\text { no topo da } \\
\text { camada } \\
\text { (MPa) }\end{array}$ & $\begin{array}{c}\text { Tensão vert } \\
\text { na base da } \\
\text { camada } \\
\text { (MPa) }\end{array}$ \\
\hline 100 & 3.13 & 0.92 & 2.5 & 2.4 \\
\hline 200 & 6.08 & 3.67 & 5.4 & 5.4 \\
\hline 300 & 8.78 & 6.37 & 8.1 & 8.0 \\
\hline 400 & 11.5 & 9.07 & 10.8 & 10.7 \\
\hline
\end{tabular}

Tabela 5 - Parâmetros para a simulação de reforço do teto das galerias do eixo por meio do elemento estrutural cable.

\begin{tabular}{c|c}
\hline Parâmetro & Valor (unidade) \\
\hline Área da seção do parafuso & $2.8 \times 10^{-4} \mathrm{~m}^{2}$ \\
\hline Perímetro do furo & $0.097 \mathrm{~m}$ \\
\hline Módulo de elasticidade do parafuso & $98.6 \mathrm{GPa}$ \\
\hline Resistência à tração do parafuso & $0.5 \mathrm{MN}$ \\
\hline Rigidez da resina & $7.5 \mathrm{~N} / \mathrm{m}$ \\
\hline Resistência coesiva da resina & $3.63 \times 10^{9} \mathrm{~N} / \mathrm{m}^{2}$ \\
\hline Resistência à fricção da resina & $0 \mathrm{grau}$ \\
\hline
\end{tabular}


Pilar-barreira entre painéis de lavra para a mina de carvão

(a)
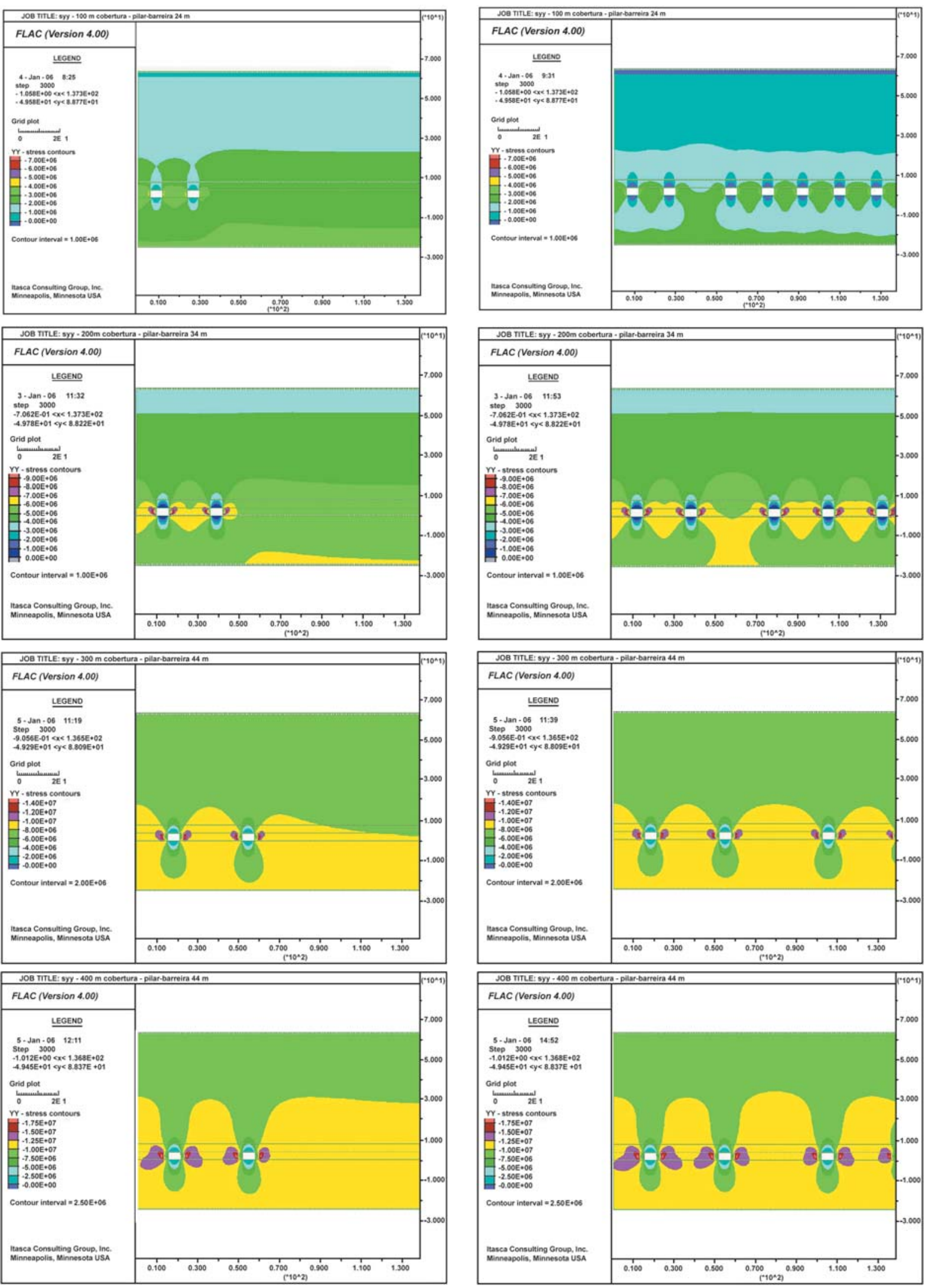

Figura 3 - Tensão vertical nas fases de escavação das galerias do eixo e das travessas do painel de lavra para (a) 100m de cobertura e $24 \mathrm{~m}$ de pilar-barreira (b) $200 \mathrm{~m}$ de cobertura e $34 \mathrm{~m}$ de pilar-barreira (c) $300 \mathrm{~m}$ de cobertura e $44 \mathrm{~m}$ de pilar-barreira (d) $400 \mathrm{~m}$ de cobertura e $44 \mathrm{~m}$ de pilar-barreira. 
André Cezar Zingano et al.

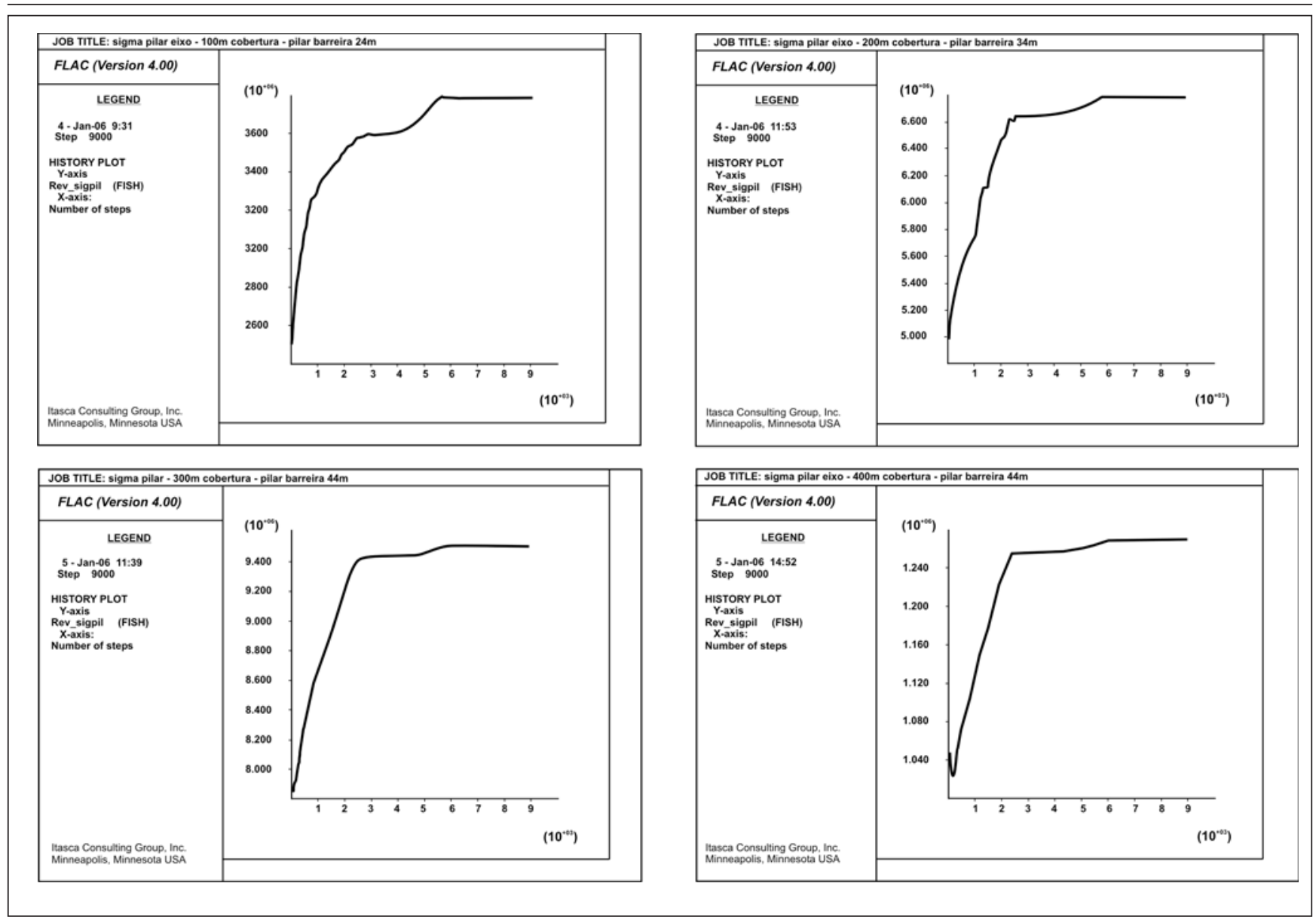

Figura 4 - Tensão vertical média do pilar do eixo próximo ao pilar-barreira para (a) 100m de cobertura e $24 \mathrm{~m}$ de pilar-barreira (b) $200 \mathrm{~m}$ de cobertura e $34 \mathrm{~m}$ de pilar-barreira (c) $300 \mathrm{~m}$ de cobertura e $44 \mathrm{~m}$ de pilar-barreira (d) $400 \mathrm{~m}$ de cobertura e $44 \mathrm{~m}$ de pilarbarreira.

mento, para verificar deformações e tensões em pontos específicos. Os principais pontos de controle são: (i) deslocamentos no teto das galerias do eixo e (ii) tensão vertical média no pilar do eixo e no pilar-barreira. Esse controle é mostrado em gráficos conforme o resultado do processamento da simulação e esses gráficos são importantes para verificação do comportamento do pilar-barreira. No próximo item são apresentados os resultados das simulações.

\subsection{Resultados}

Nas Figura 3 e 4, encontram-se os resultados das simulações numéricas para a aplicação do pilar-barreira. As figuras são as seguintes: (Figura 3) distribuição de tensões ao redor das escavações para a etapa de escavação das galerias do eixo e para a etapa de escavação das travessas do painel de lavra e (Figura 4) tensão vertical média no pilar do eixo próximo ao pilar-barreira.

Com base nos resultados, pode-se observar que, praticamente, não ocorre alteração do estado de tensões nos pilares, quando da escavação das travessas do painel de lavra nos

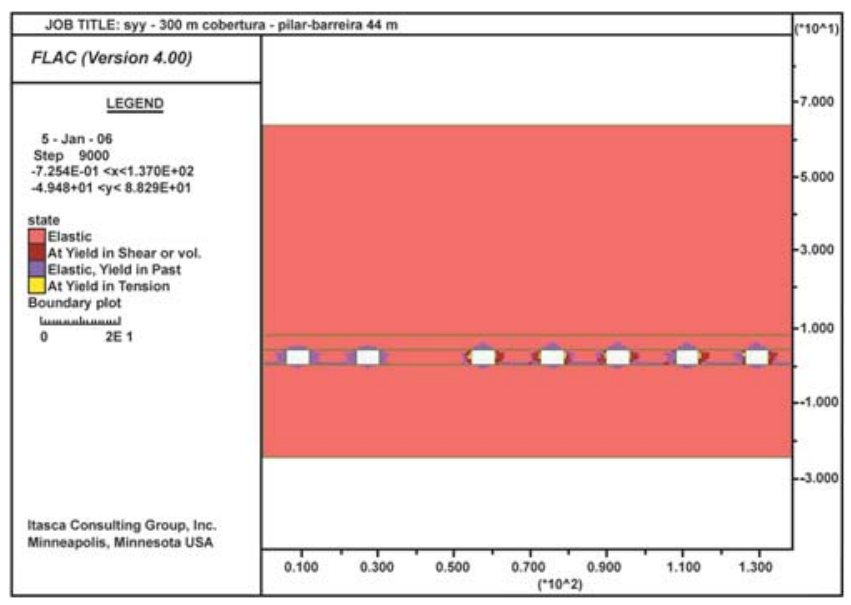

Figura 5 - Estado de plasticidade do maciço rochoso para espessura de cobertura de $200 \mathrm{~m}$ e pilares de $12 \mathrm{~m}$ de lado.

pilares do eixo. Isto ocorre porque parte das tensões são suportadas pelo pilar-barreira.

Nos modelos com 100 m de profundidade, ocorrem um maior efeito do pilar-barreira, porque os pilares são muito me- 
nores que o pilar-barreira. Nos modelos com maior profundidade, o efeito do pilar-barreira é menor, porque os pilares são muito grandes e achatados, podendo absorver altas tensões. Entretanto, nesses pilares, a zona de plasticidade nas paredes dos pilares é maior, devido a pressão vertical na parede ser alta e provocar maior deformação dessas paredes. Portanto devese realizar a contenção das paredes dos pilares.

Não há sinais de aumento da zona de plasticidade dos pilares do eixo, quando ocorre a escavação das travessas do painel de lavra.

Na profundidade de $200 \mathrm{~m}$ para pilares de $12 \mathrm{~m}$, a zona de plasticidade é maior que para pilares de $20 \mathrm{~m}$, mostrando que os pilares estão próximos da ruptura total (Figura 5).

Ocorre pequeno aumento da tensão média do pilar do eixo próximo ao pilar-barreira, quando ocorre a lavra do painel de produção. Esse aumento varia entre 0.04 e $0.5 \mathrm{MPa}$, com redução desse aumento à medida que a profundidade aumenta, porque os pilares de sustentação são grandes e com alta capacidade de carga.

O deslocamento do teto da galeria do eixo próximo ao pilar-barreira aumente com a profundidade da camada (Figura 6), devido à tensão horizontal aplicada ao teto imediato. A deflexão máxima é de $4.5 \mathrm{~mm}$. Essa deflexão tem pequeno aumento, quando ocorre a lavra do painel de produção, sendo menor que $0.5 \mathrm{~mm}$.

\section{Conclusões e recomendações}

Em locais onde a camada de carvão é mais profunda, os autores desse trabalho acreditam que possa existir a possibilidade de reduzir o tamanho dos pilares nos painéis de lavra devido à presença do pilar-barreira que recebe boa parte das pressões verticais da cobertura.

Em regiões com cobertura acima de 400 m, é possível realizar a lavra em recuo, pois a subsidência na superfície será pequena e aumenta a recuperação da jazida. Entretanto essa prática deve ser muito bem planejada antes de sua aplicação, porque envolve o risco do abatimento prematuro do teto e esmagamento de pilares.

A estimativa das propriedades geomecânicas da camada Bonito é motivo de discussão e pesquisa no momento, não existindo um consenso entre as empresas sobre esse assunto. Os autores desse trabalho acreditam que isso reforça a heterogeneidade dessa camada de carvão, a qual abrange uma vasta área na região de Criciúma. Portanto cada jazida (ou mina) deve ser investigada separadamente.

A aplicação de pilar-barreira parece sem utilidade quando não ocorre a lavra com recuperação de pilares ou quando não ocorre a ruptura de pilares. Entretanto a aplicação de pilarbarreira para o caso das minas de carvão de Santa Catarina tem objetivo de prevenir contra colapso massivo de pilares e ruptura de pilares antigos (com mais de 10 anos), protegendo-se o eixo da mina.

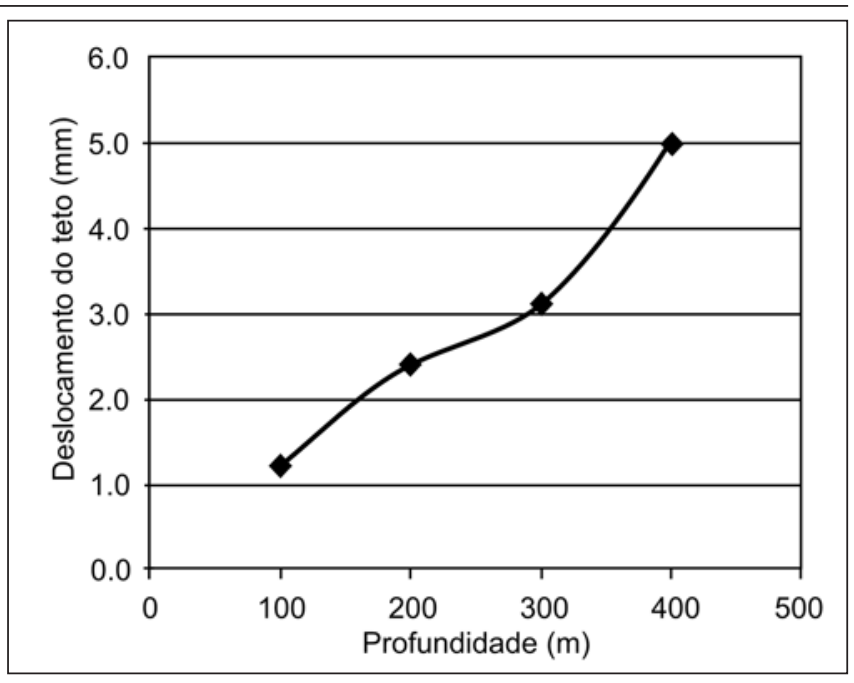

Figura 6 - Deslocamentos do centro do teto da galeria do eixo próximo ao pilar-barreira em função da profundidade.

A simulação de ruptura de um pilar dentro do painel de lavra foi realizada em alguns modelos. Entretanto os resultados que foram obtidos mostram que o pilar-barreira cumpriu sua função de proteção do eixo da mina, onde os pilares, praticamente, não sofreram alteração na tensão vertical.

\section{Agradecimentos}

Os autores gostariam de agradecer ao corpo técnico e diretorias das empresas que colaboraram para a realização desse trabalho.

\section{Referências bibliográficas}

BIENIAWSKI, Z.T. Engineering classification of jointed tock masses, Transactions of South Africa Institute of Civil Engineers, v. 15, p. 335-344, 1973.

BIENIAWSKI, Z.T. Engineering rock mass classification. EUA: Jonh Wiley \& Sons, 1989. 251 p.

CAMPOLI, A.A., MUCHO, T.P., ZIPF, R.K. Bump control design protocol for room-and-pillar coal mining, Proc. Mechanics and Mitigation of Violent Failure in Coal and Hard Mines, US Dep. of the Interior, Bureau of Mines, Pittsburgh, PA, Spetial Publication 01-95, p. 181-199, 1995.

CHASE, F., MARK, C., HEASLEY, K. Deep cover extraction in US coalfields, International Conference on Ground Control in Mining. WVU, EUA: Peng Ed.Cheif, 2002.

HOEK, E., BROWN, E.T. Practical estimation of rock mass strength. Int. J. of Rock Mech. and Min. Sci., v. 34, p. 1165-1186, 1997.

MANUAL DO FLAC-2D versão 4.0, Structural Elements, Itasca Softwares, 2002.

MARK, C. Overview of ground control research for underground coal mines in the United States, NIOSH. 8 p. (Paper baixado da homepage da NIOSH).

PENG, S.S. Coal Mine Ground Control. New York: John Wiley \& Sons, 1986, $491 \mathrm{p}$.

ZINGANO, A.C. Modelamento geomecânico para o dimensionamento de pilares de carvão. PPGEM - UFRGS, 2002. 199p. (Tese de Doutorado).

Artigo recebido em 24/02/2006 e aprovado em 01/12/2006. 